\title{
CFRP-Recycling Following a Pyrolysis Route: Process Optimization and Potentials
}

\author{
L. O. MeYeR* AND K. Schulte \\ Technische Universität Hamburg-Harburg, Institute of Polymers \\ and Composites, Denickestrasse 15, 21073 Hamburg, Germany \\ E. GROVE-NIELSEN \\ ReFiber ApS, Folvigvej 8, Vile, DK-7870 Roslev, Denmark
}

\begin{abstract}
Pyrolysis is a well known method to recover carbon fibers from composite waste. In order to bring these recycled carbon fibers back into new composites, and to provide a 'closed loop' for this material, their properties have to be investigated and proved suitable for new products. In a former study a strong influence of the pyrolysis process on the surface of the recovered fibers was found. This in turn influenced other properties like fiber strength, electrical properties and fiber-matrixadhesion. These results offer the possibility to control individual properties of recycled carbon fibers and their composites, but on the other hand they indicate a necessity for process optimization in order to provide a high quality of the recycled fibers. In this study different process parameters during pyrolysis were investigated and optimized in order to provide the reclaimed carbon fibers with properties close to new fibers. The optimization was done by labscale pyrolysis experiments performed in a thermogravimetric analyzer (TGA), with variation of pyrolysis temperature, isothermal dwell time and oven atmosphere, respectively. The recovered fibers were analyzed by scanning electron microscopy and Raman spectroscopy. Finally a pyrolysis test on a semi-industrial-scale was successfully performed to demonstrate the technical viability of the optimized process parameters.
\end{abstract}

KEY WORDS: CFRP, carbon fibre, epoxy, recycling, pyrolysis.

\section{INTRODUCTION}

C ARBON FIBER REINFORCED epoxies (CFRPs) are widely used as structural engineering material for example in aircraft production and sports equipment industries. Due to their high potential for lightweight applications other industries, such as the automotive and wind power industries, are also very interested in using these materials.

\footnotetext{
*Author to whom correspondence should be addressed. E-mail: 1.meyer@tuhh.de

Figure 5 appears in color online: http://jcm.sagepub.com
} 
Today these new applications of CFRPs are limited by the high price for carbon fibers, the limited availability, expensive costs for disposal of production waste and end-of-life-parts and, especially in the case of the European automotive industry, the missing recycling processes. All these restrictions can be reduced by the development of an appropriate recycling process, which allows returning recycled carbon fibers into production processes.

The recovery of carbon fibers from CFRP waste alone does not provide a 'closed loop' for this material. The second important step is to bring the fibers back into production of composite parts. Therefore, a proper investigation and optimization of the properties of the recycled carbon fibers is essential. If the fibers do not fit the customers' demands (i.e., cheaper than new fibers, good properties), an application in new composite products will not take place and the material loop will remain unclosed.

A recycling process that is suitable for upscaling into industrial scale has to fulfill different requirements: low energy consumption, low cost and finally good properties of the reclaimed fibers. Among the different known recycling processes, pyrolysis is very promising to fit these demands [1].

During pyrolysis the epoxy-macromolecule is transferred into smaller molecules at temperatures above $350^{\circ} \mathrm{C}$ in an oven. These smaller molecules evaporate from the material and, due to their high calorific value, can be used as energy source for the process. Together with the fibers an amount of pyrolytic carbon bonded to the fiber surface remains in the oven [2]. The amount of pyrolytic carbon and the mechanical properties of the reclaimed fibers strongly depend on the process parameters as oven atmosphere, temperature, heating rate and others [3]. Consequently, it is possible to influence the fiber properties by these parameters and an optimization is necessary in order to reclaim fibers that fit the demands for applications in new composites and new products.

First, pyrolysis experiments were carried out in a very simple gas fired batch oven process. In this process approximately $50 \mathrm{~kg}$ of prepreg were placed inside the oven chamber. The prepreg-scrap was pyrolyzed at $700,900,1100$, and $1300^{\circ} \mathrm{C}$, respectively, and the mechanical, electrical, and surface properties of the recovered fibers were characterized. Results from these tests have been presented elsewhere [3]. A strong influence of pyrolysis temperature on all properties was found, whereas changes in the fiber surface seemed to be most important, because the changes of mechanical and electrical properties are more or less influenced by the fiber surface condition. In case of pyrolysis at $700^{\circ} \mathrm{C}$ the fiber surface is covered with a layer of pyrolytic carbon, which consists of residues of the decomposed epoxy matrix. This surface layer leaves the mechanical properties unchanged compared to virgin carbon fibers, but the contact resistance between the fibers is increased and the adhesion to a new matrix is decreased. At higher pyrolysis temperatures the amount of pyrolytic carbon is reduced. At $1300^{\circ} \mathrm{C}$ the pyrolytic carbon was completely removed and a smooth fiber surface was observed. In addition, the surface of the carbon fibers was found to be highly activated. Consequently, the fiber strength suffered from high pyrolysis temperatures, while the contact resistance between crossing fibers was reduced and a good adhesion of these fibers to a new polymer matrix was found. These results indicated a requirement for an optimization of the pyrolysis parameters, which was done in this study.

In this study the influence of different process parameters on the pyrolysis of CFRPprepreg waste, generated during aircraft production, is investigated by thermogravimetric analysis (TGA). Using the results from these experiments further optimization of the pyrolysis parameters was performed by TGA experiments with uncured prepreg samples. The recovered fibers were investigated by Raman-spectroscopy and SEM. Finally, a 
pyrolysis test run was performed on semi-industrial scale in order to confirm the transferability from labscale to industrial processes.

\section{MATERIALS}

For all experiments presented here prepregs of the type Hexply 913C/HTA were used. This prepreg system, supplied by Hexcel Composites, consists of high tenacity carbon fibers (HTA, Toho-Tenax) in a woven structure, embedded in the $125^{\circ} \mathrm{C}$-curing epoxymatrix 913C (Hexcel Composites) with a fiber volume content of $60 \%$, which corresponds to a nominal matrix weight content of $31.8 \%$.

The prepreg cutoff is generated during production of many CFRP-parts. The sheets had a size from $5 \times 5 \mathrm{~cm}$ up to $70 \times 70 \mathrm{~cm}$. Before pyrolysis the release paper was removed while the (poly)-propylene separation foil was left on the prepregs. Samples for the pyrolysis tests in a pilot plant were cut to a similar size of $5 \times 5 \mathrm{~cm}$.

\section{EXPERIMENTAL}

\section{Labscale Pyrolysis}

The experiments were carried out in a TGA Q500 Highres ${ }^{\circledR}$ thermogravimetric analyzer by TA Instruments. The influence of the oven atmosphere, the maximum process temperature and isothermal dwell times on the pyrolysis results were investigated in the experiments. The heating rate of the device was set to $10^{\circ} \mathrm{C} / \mathrm{min}$ with a gas flow rate of $60 \mathrm{~mL} / \mathrm{min}$. For the fundamental investigation of the pyrolysis process of the epoxy resin and the carbon fibers in nitrogen and synthetic air atmosphere as well as for analysis of the recovered fibers the Highres ${ }^{\circledR}$ (high resolution) option was used. In this mode the TGA is using dynamic heating rates with a nominal heating rate of $10^{\circ} \mathrm{C} / \mathrm{min}$. The heating rate is slowed down or even stopped when weight loss is detected in order to achieve a higher resolution of the different decomposition steps. Platinum pans were used for all experiments.

All other pyrolysis-tests performed in the TGA were run at a fixed heating rate of $10^{\circ} \mathrm{C} / \mathrm{min}$. The sample weight for all experiments was chosen between 15 and $20 \mathrm{mg}$.

\section{Fiber Characterization}

Due to the very small amount of recovered fibers of only $10-15 \mathrm{mg}$ it was not possible to perform mechanical or electrical tests on the recovered fibers. As described before, the properties of the fibers are dominated by the fiber surface condition. Therefore, in this article the fiber characterization was concentrated on the fiber surface.

Scanning electron microscopy (SEM) enabled to pay special attention to the pyrolytic carbon residues on the fibers and their structure.

Raman spectroscopy is most often used to determine the so-called defect density of carbon fibers, which is the ratio between the intensity of the defect peak divided by the sum of the intensity of the defect and graphite peak. For highly graphitized carbon fibers, like high-modulus fibers (HM), it should be directly possible to observe changes of the fiber surface. Pyrolytic carbon as well as an activation of the fiber surface [4] would lead to an 
increase in defect density, while the spectrum for the untouched fibers is dominated by the graphite peak. However, in the case of the HTA-fibers the degree of graphitization is low compared to HM fibers. Therefore, already the spectrum of as-produced fibers exhibits a higher defect density and changes cannot be detected as clearly. Instead, the presence of organic residues (the degree of carbonization of the former epoxy matrix) can be identified by the sharpness of the peaks $[5,6]$. If this occurs it can be stated, that the decomposition of the epoxy is incomplete and there are organic matrix residues.

\section{Optimized Pyrolysis}

The parameters for the optimized pyrolysis were determined from the results of labscale pyrolysis and fiber surface characterization. The experiments were carried out in a semiindustrial scale oven at the company ReFiber. The oven consists of a heating chamber with a barrel inside. The prepreg cutoffs were placed inside the barrel and the barrel was turned during pyrolysis to agitate the material and to obtain a homogeneous quality of the recycled fibers. The oven is equipped with electrical heating and is run as a batch process.

\section{RESULTS AND DISCUSSION}

\section{Labscale Pyrolysis}

CFRP consists of two different phases, epoxy resin and carbon fibers. The objective of the recycling process is to remove only one phase (the matrix) without affecting the second phase (the carbon fibers). Hence, the decomposition and oxidation behavior of both phases was investigated separately in a first set of experiments.

\section{PYROLYSIS OF NEAT RESIN}

The decomposition of the epoxy resin, which was extracted from the prepreg by washing in acetone and subsequent drying in vacuum, was investigated by thermogravimetric analysis using the Highres ${ }^{\circledR}$ mode, as described earlier. The obtained weight loss vs temperature curves, taken from measurements in nitrogen and synthetic air, respectively, are shown in Figure 1 (a).

It is obvious that the devolution of the decomposition reaction is different for both atmospheres. In nitrogen atmosphere the decomposition starts with the release of small molecules at $\sim 250^{\circ} \mathrm{C}$, followed by a single decomposition step of the organic epoxy matrix at $\sim 380-400^{\circ} \mathrm{C}$. Above $450^{\circ} \mathrm{C}$ this decomposition reaction is finished and only small changes of the sample weight were detected during further heating. The residual weight at $600^{\circ} \mathrm{C}$ is $19 \%$ which indicates a formation of pyrolytic carbon, which is formed from the epoxy matrix during pyrolysis. It can be said that, due to the pyrolytic carbon residues, the aim to achieve a complete separation of fiber and matrix was not reached.

In the case of pyrolysis in synthetic air atmosphere the decomposition is a combination of thermal degradation, like in the nitrogen atmosphere, and oxidation of the matrix residues. In the beginning the release of smaller molecules takes place in the same manner, but already at $310^{\circ} \mathrm{C}$ a first major weight loss can be detected, which can be related to oxidation of polar groups and side chains of the epoxy molecule [7]. At $400^{\circ} \mathrm{C}$ the second degradation step is detected. This step can, like in the nitrogen atmosphere, be related to 

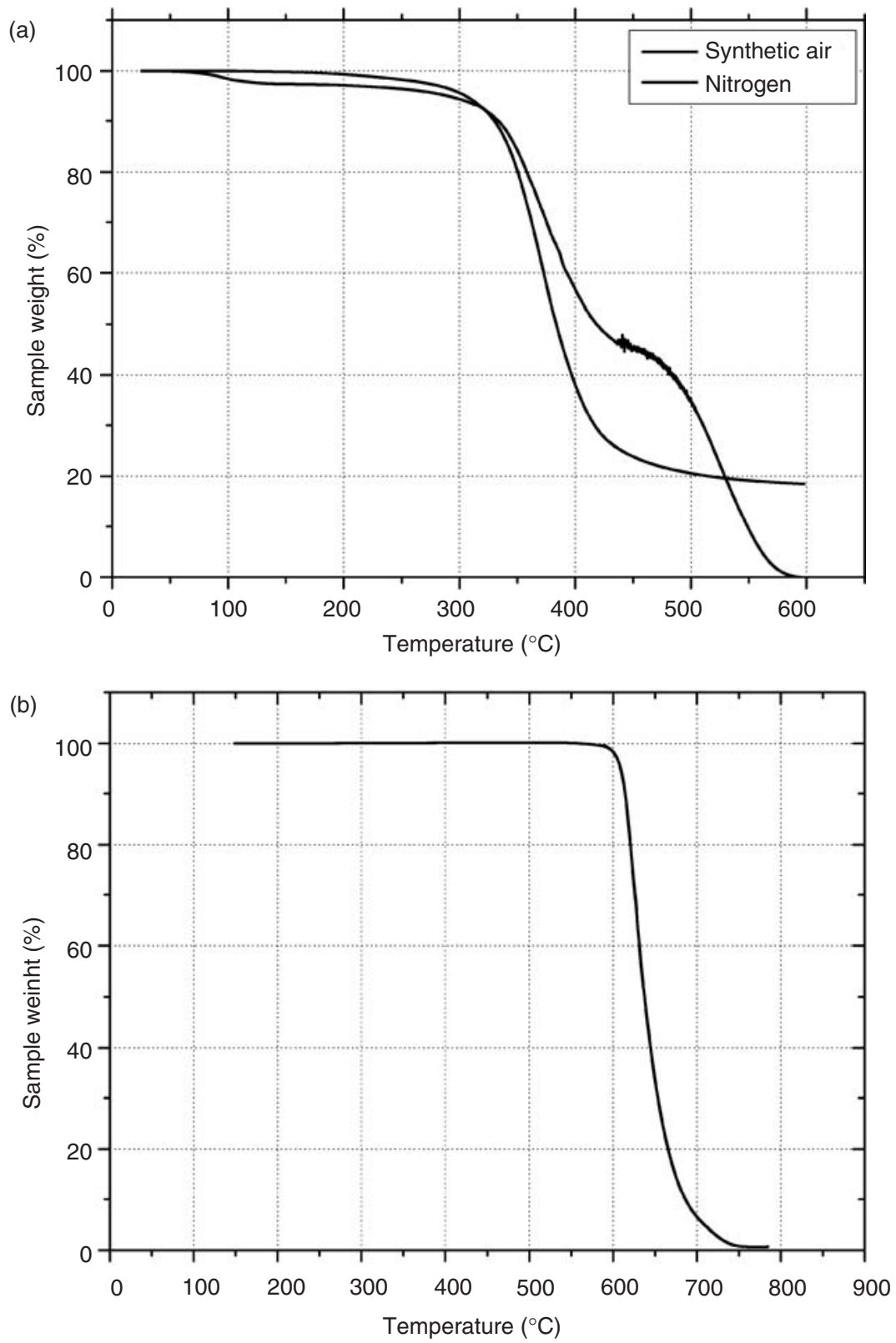

Figure 1. Sample weight over temperature. (a) Pyrolysis of epoxy resin in nitrogen and air; (b) Oxidation of carbon fibers.

the decomposition of the macromolecules by cracking of covalent bonds. The smaller molecule fragments of this reaction evaporate at this temperature. However, the residual weight after this reaction is around $50 \%$ at $450{ }^{\circ} \mathrm{C}$ and is therefore much higher, compared to pyrolysis in nitrogen. Consequently, the amount of pyrolytic carbon formed during this reaction is much bigger in air compared to nitrogen atmosphere. In this temperature regime pyrolysis in inert conditions is more effective. This behavior is described in Ref. [8] 
and is caused by the fact that, during the decomposition step at $310^{\circ} \mathrm{C}$, the polar groups of the epoxy molecule are oxidized. Therefore, the residues after this reaction have higher carbon content and oxidation at higher temperatures is required, in addition to thermal degradation, in order to remove them. The next decomposition reaction takes place at $540-580^{\circ} \mathrm{C}$. At this temperature the pyrolytic carbon, which mainly has a disordered carbon structure, is completely removed by oxidation.

\section{OXIDATION OF CARBON FIBERS}

The carbon fibers should be stable at high temperatures in an inert environment. Therefore, only an investigation of their oxidation stability was performed by a TGA experiment in synthetic air. The Highres ${ }^{\circledR}$-mode was used for this experiment. From the weight loss over temperature curve (Figure 1(b)) it can be seen that the carbon fiber is not oxidized below $600^{\circ} \mathrm{C}$.

By comparing the results from pyrolysis of resin and fibers in air (Figure 1(a) and (b)) it can be seen, that there is a small temperature gap between 580 and $600^{\circ} \mathrm{C}$, where it should be possible to separate the carbon fibers from the pyrolytic carbon by partial oxidation. According to these results the fibers should not be damaged by this process.

\section{PYROLYSIS OF CFRP}

Only the behavior of the single components during pyrolysis was investigated so far. After this elementary work, further experiments are required to investigate the pyrolysis of the prepregs and to investigate if complete removal of the matrix from the fibers can be achieved. The parameters studied in this article are maximum temperature and isothermal dwell times. All these experiments were carried out using a fixed heating rate of $10^{\circ} \mathrm{C} / \mathrm{min}$.

The residual weight of prepreg samples, pyrolyzed in both air and nitrogen atmosphere, with a variation of the maximum process temperature, was detected. After reaching the final temperature the samples were immediately cooled down to room temperature. The results are shown in Figure 2.

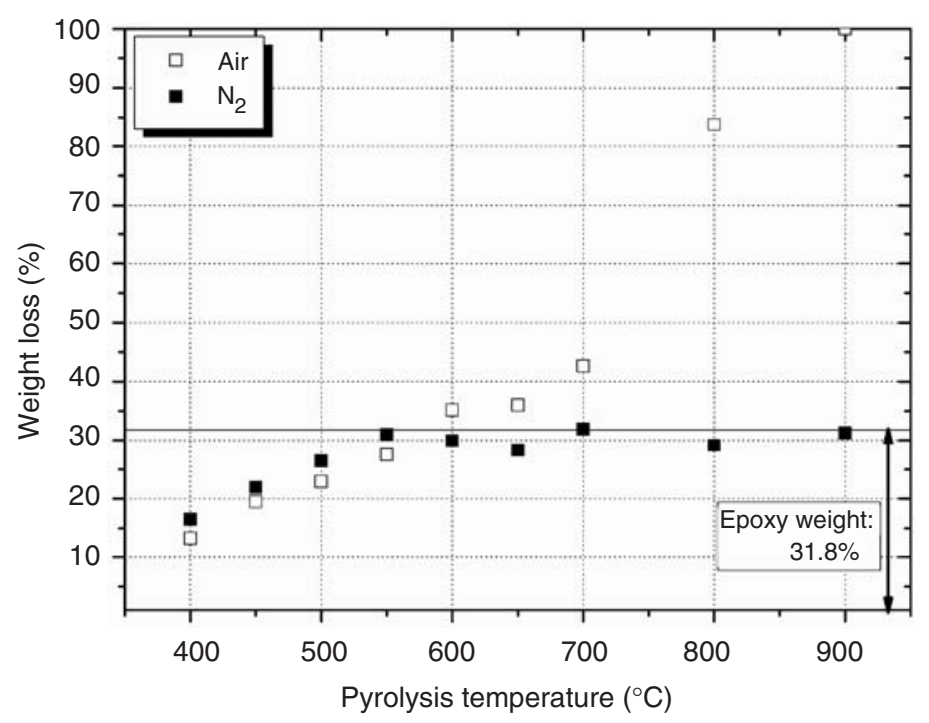

Figure 2. Weight loss of the prepreg samples at different pyrolysis temperatures. 
Between 400 and $550^{\circ} \mathrm{C}$ the weight loss measured in both atmospheres is still below the theoretical weight of the matrix, indicating pyrolytic carbon residues. In this temperature range the pyrolysis leads to better results in inert atmosphere, as expected from Figure 1(a). Above $550^{\circ} \mathrm{C}$ the results are changing, as in air the oxidation of the pyrolytic carbon starts. In the nitrogen atmosphere, on the other hand, there is no additional weight loss during further heating. This allows the conclusion, that pyrolysis in nitrogen is always leading to pyrolytic carbon residues, even at high temperatures such as $900^{\circ} \mathrm{C}$. In oxygen a complete removal of the former matrix can be achieved at $\sim 600^{\circ} \mathrm{C}$ due to oxidation, which correlates well with the investigation of the neat epoxy. A further weight loss at $650^{\circ} \mathrm{C}$ and above is related to oxidation of the carbon fibers. This results in a strong decrease of the mechanical properties of the fibers and consequently temperatures in this range should be avoided when pyrolyzing in the presence of oxygen.

In a third series of measurements the influence on isothermal dwell times at maximum pyrolysis temperatures between $400^{\circ}$ and $600^{\circ} \mathrm{C}$ was examined. The weight loss detected in these experiments is shown in Figure 3. For the measurements performed in nitrogen atmosphere, no explicit influence of isothermal dwell time can be seen. For the measurements at $400^{\circ} \mathrm{C}$ an increase in weight loss was detected for the first $30 \mathrm{~min}$. At $500^{\circ} \mathrm{C}$ this increase is already much smaller and for $600^{\circ} \mathrm{C}$ it even disappears. Hence, the reaction seems to be time dependent only in the lower temperature regime. For longer dwell times or higher pyrolysis temperatures no further changes in weight loss were found. Therefore, neither high pyrolysis temperatures above $600^{\circ} \mathrm{C}$, nor long dwell times of more than $30 \mathrm{~min}$ are required when pyrolysis is performed in nitrogen atmosphere.

An increase in weight loss with dwell time was found for the oxidative atmosphere. Hence, it can be seen that the oxidation reaction is much more time dependent. This behavior is different to the depolymerization in inert atmosphere. At $600^{\circ} \mathrm{C}$ the weight loss is reaching high values at long dwell times. This indicates the oxidation of the carbon fibers and therefore the carbon fibers should be exposed to this temperature only for short time in order to avoid oxidative fiber damage.

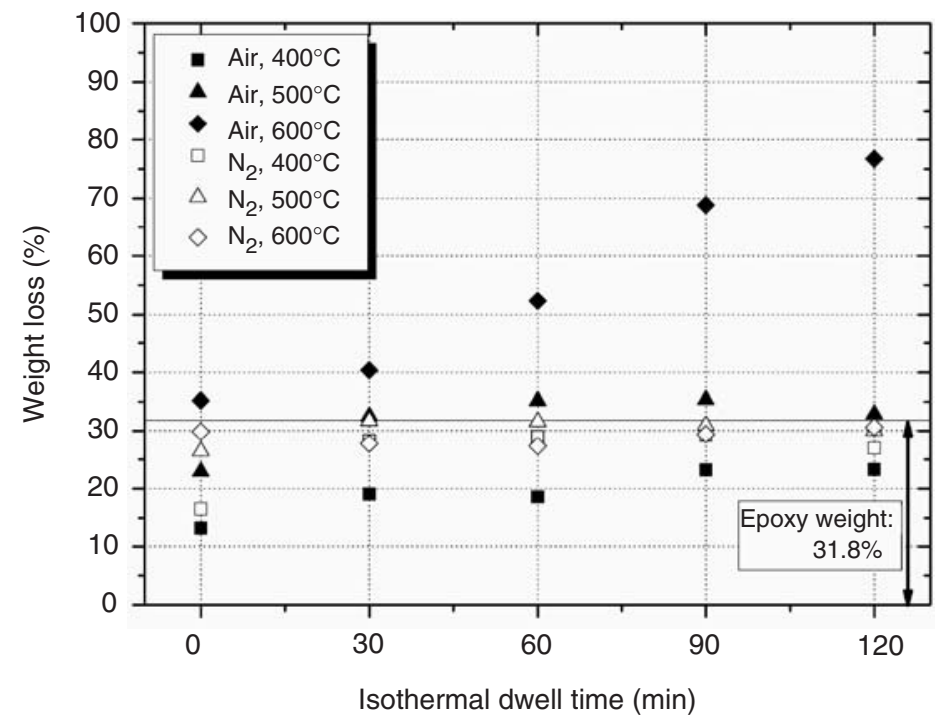

Figure 3. Weight loss after isothermal dwell time at maximum temperature. 


\section{Fiber Characterization}

\section{SCANNING ELECTRON MICROSCOPY}

From the large number of different types of recycled carbon fibers in the labscale pyrolysis tests, only six were chosen for the discussion. With these materials it is possible to describe the influence of the oven atmosphere, pyrolysis temperature, and isothermal dwell time on the surface properties of the recovered fibers.

SEM photographs of the reclaimed fibers are shown in Figure 4. The influence of pyrolysis temperature on the fiber surface is obvious for both atmospheres - nitrogen and synthetic air. The fibers pyrolyzed in nitrogen at $500^{\circ} \mathrm{C}$ (Figure 4(a)) are completely covered with a smooth layer of pyrolytic carbon and are therefore still bonded together. At $700^{\circ} \mathrm{C}$ in $\mathrm{N}_{2}$ (Figure 4(b)) the amount of pyrolytic carbon is decreased and the fibers are more or less separated.

In the case of oxidative atmosphere, the influence of temperature appears even more explicit. At $500^{\circ} \mathrm{C}$ in air (Figure $4(\mathrm{~d})$ ) the fibers are still covered by matrix residues.

(a)

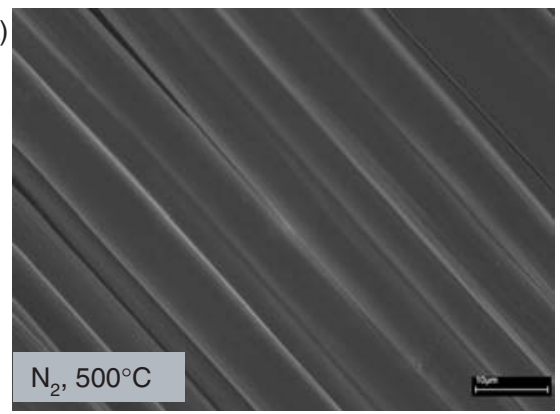

(c)

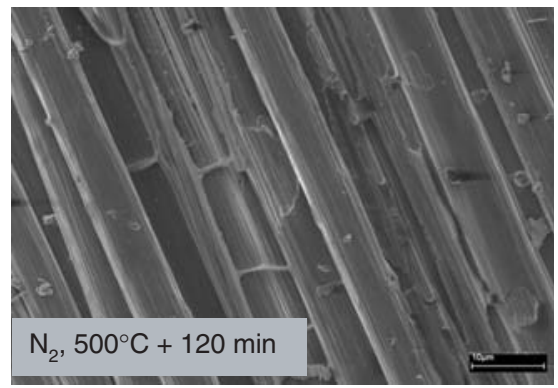

(e)

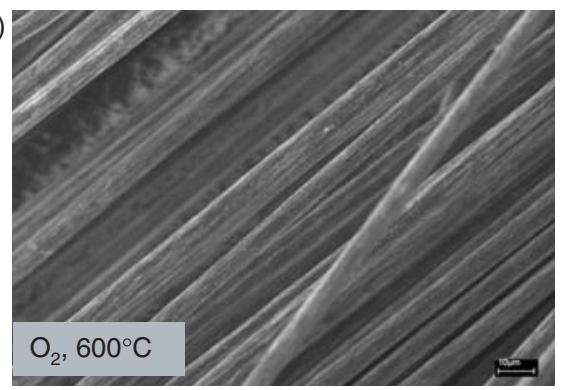

(b)

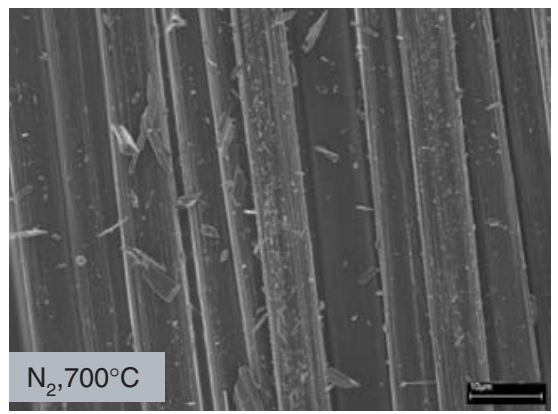

(d)

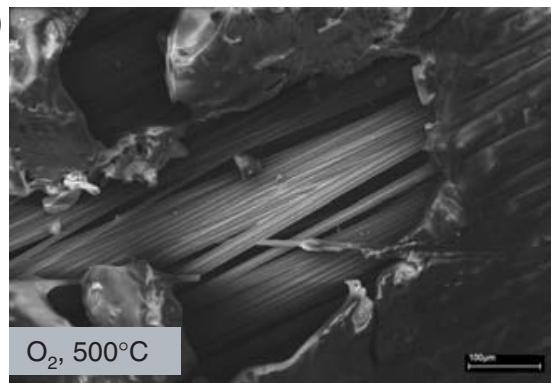

(f)

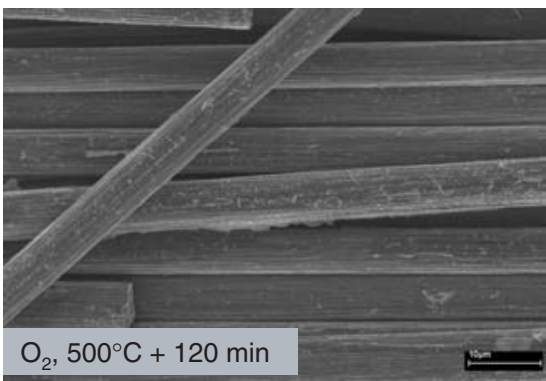

Figure 4. SEM-images of the recovered fibers. (a) $500^{\circ} \mathrm{C}$ in nitrogen without dwell time, (b) $700^{\circ} \mathrm{C}$ in nitrogen without dwell time, (c) $500^{\circ} \mathrm{C}$ in nitrogen with $120 \mathrm{~min}$. dwell time, (d) $500^{\circ} \mathrm{C}$ in air without dwell time, (e) $600^{\circ} \mathrm{C}$ in air without dwell time, and (f) $500^{\circ} \mathrm{C}$ in air with $120 \mathrm{~min}$ dwell time. 
At $600^{\circ} \mathrm{C}$ in air (Figure 4(e)) these residues are completely removed and the fiber surface appears clean and smooth.

The influence of isothermal dwell time is comparable to the influence of temperature. In nitrogen, only small changes are observed with increasing dwell time. In the SEM images the amount of pyrolytic carbon is slightly decreased after 120 min dwell time (Figure 4(c)). In the presence of oxygen, again, the influence of dwell time is more obvious. Without dwell time the fibers are still embedded in a thermally degraded matrix (Figure 4(d)). After 120 min dwell time the result is now completely different. The fibers are separated and the image shows only a very low amount of pyrolytic carbon (Figure 4(f)).

RAMAN-SPECTROSCOPY

Raman spectroscopy was chosen as a second method for the investigation of the fiber surfaces. This method gives further insight into the carbon structure on the fiber surface

(a)

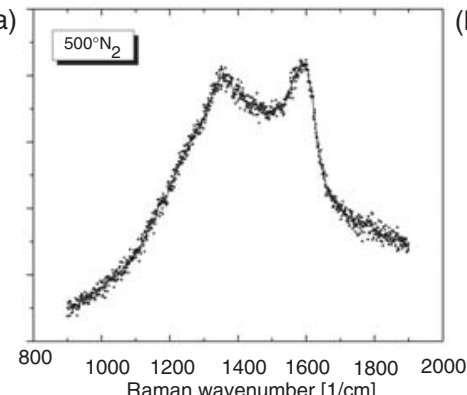

(c)

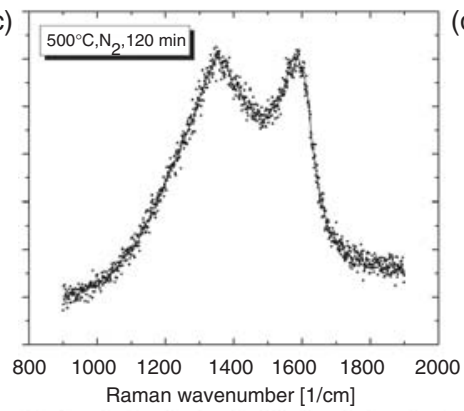

(e)

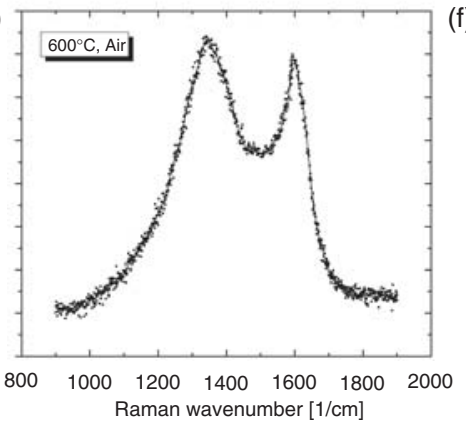

(b)

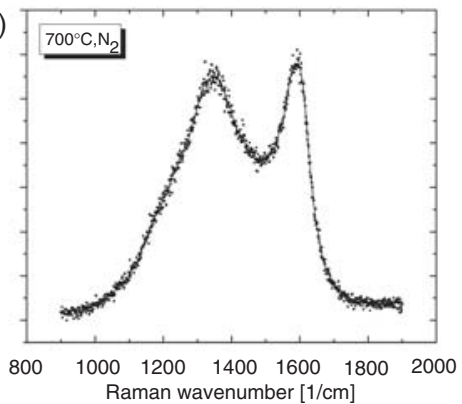

(d)

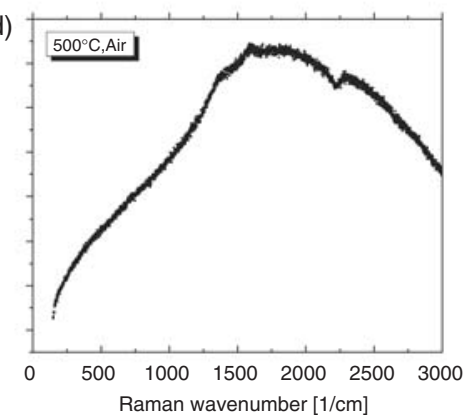

(f)

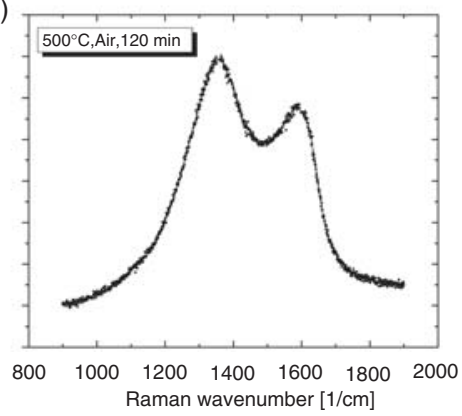

Figure 5. Raman-spectra of the recovered fibers. (a) $500^{\circ} \mathrm{C}$ in nitrogen without dwell time, (b) $700^{\circ} \mathrm{C}$ in nitrogen without dwell time, (c) $500^{\circ} \mathrm{C}$ in nitrogen with $120 \mathrm{~min}$. dwell time, (d) $500^{\circ} \mathrm{C}$ in air without dwell time, (e) $600^{\circ} \mathrm{C}$ in air without dwell time, (f) $500^{\circ} \mathrm{C}$ in air with $120 \mathrm{~min}$. dwell time. 
and the amount of polymeric residues from the former matrix remaining on the surface. The obtained Raman spectra are shown in Figure 5.

The influence of the pyrolysis temperature in inert atmosphere can be seen when comparing Figure 5(a) and (b). The defect density of both samples is similar, but the sharpness of the D- and G-peak are more pronounced at higher pyrolysis temperatures. This can be explained by a carbonization of the pyrolytic carbon on the fiber surface. At $500^{\circ} \mathrm{C}$ the pyrolytic carbon contains some organic residues leading to wider peaks, while the peaks become narrow and sharp at $700^{\circ} \mathrm{C}$, which can be related to a purification of the carbon on the fiber surface. The results correspond well with the observation made during the pyrolysis experiments, where the weight loss was much higher at $700^{\circ} \mathrm{C}$ than at $500^{\circ} \mathrm{C}$, but also when comparing with the SEM images.

The influence of isothermal dwell time at maximum temperature is not that explicit in the nitrogen atmosphere. The Raman spectrum of the fibers pyrolyzed at $500^{\circ} \mathrm{C}$ with $120 \mathrm{~min}$ dwell time (Figure 5(c)) shows only a very small change when compared to the fibers pyrolyzed without dwell time (Figure 5(a)). This again corresponds to the observations made during pyrolysis experiments and in the SEM photographs. Therefore, it can be concluded, that the thermal decomposition of the epoxy resin in inert atmosphere is temperature dependent, but not very much time dependent.

The Raman-spectra of the fibers pyrolyzed in air atmosphere show a strong influence of time and temperature. At $500^{\circ} \mathrm{C}$ without dwell time, the Raman spectrum consists of one broad single peak (Figure 5(d)). This is not a typical spectrum of a carbon fiber and indicates the presence of a big amount of organic residues on the fiber surface. By increasing the pyrolysis temperature to $600^{\circ} \mathrm{C}$ (Figure 5(e)), as well as by an isothermal dwell time of $120 \mathrm{~min}$ at $500^{\circ} \mathrm{C}$ these organic residues are more or less removed, as shown in the SEM images. The spectra show two clearly separated sharp peaks. However, the defect density of the fibers pyrolyzed in air seems to be slightly increased compared to the fibers recycled in inert conditions. This might be due to oxidation of the fiber surface.

From the results of the surface characterization it can be concluded that the decomposition reactions in the inert atmosphere are more dependent on the process temperature, while oxidation processes are dependent on time and temperature.

The results are in good agreement with the conclusions made earlier from the weight-loss data. For all materials pyrolyzed in nitrogen an amount of remaining pyrolytic carbon was found on the fiber surface. By the influence of increased pyrolysis temperature and long dwell time it is possible to reduce the organic residues slightly. In oxygen-containing atmosphere it is possible to remove the pyrolytic carbon completely. This can be achieved by process temperatures between 500 and $600^{\circ} \mathrm{C}$. At $500^{\circ} \mathrm{C}$ the time of exposure should be $2 \mathrm{~h}$ or more. At $600^{\circ} \mathrm{C}$ the risk of damaging the fibers by oxidation has to be mentioned.

\section{Pyrolysis Test Run}

From the results presented above optimized pyrolysis parameters were derived for the test run at ReFiber. During pyrolysis in a larger scale, problems can arise which are not known from labscale. One of these is the fact that the oxidation of organic material at elevated temperatures is exothermic. Therefore, a first pyrolysis step in nitrogen at $550^{\circ} \mathrm{C}$ for $2 \mathrm{~h}$ was chosen to remove the organic material without the risk of uncontrolled temperature increase. Then the material was allowed to cool down below $200^{\circ} \mathrm{C}$. In a second step the pyrolytic carbon was removed from the fibers by partial oxidation around $550^{\circ} \mathrm{C}$. 
Table 1. Fiber strength of as-produced and recycled carbon fibers. Weibull mean value for the fiber strength and dimensionless Weibull-modulus $m$.

\begin{tabular}{lcc}
\hline & $\boldsymbol{\sigma}_{\mathbf{6 3} \%}(\mathrm{MPa})$ & $\boldsymbol{M}$ () \\
\hline HTA-fiber, as produced & 3712 & 5.04 \\
HTA-fiber from optimized pyrolysis & 3568 & 4.48 \\
\hline
\end{tabular}

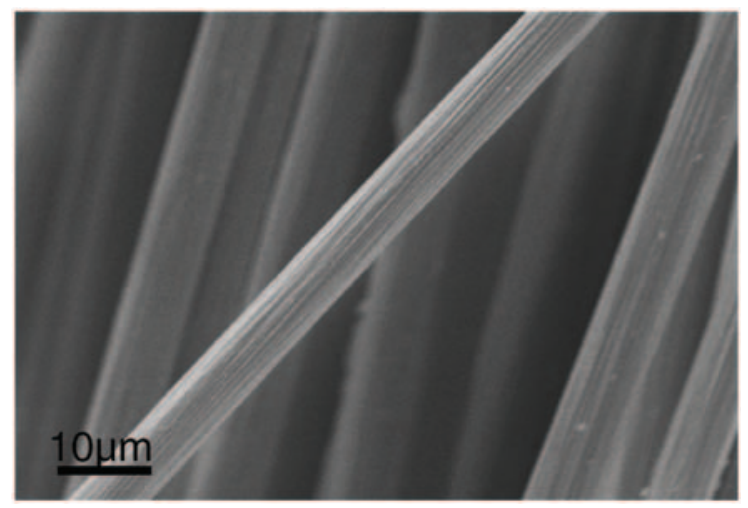

Figure 6. SEM-image of carbon fibers recovered by optimized pyrolysis route.

The mechanical properties of the recovered fibers were measured in a single fiber tensile test according to ASTMD-3379-75. Because of the high scatter in strength of the brittle carbon fibers at least 50 fibers were tested for each material. The analysis of the obtained test results was done using the Weibull theory [9] leading to $\sigma_{63} \%$ as a mean value for the fiber strength and the dimensionless Weibull modulus $m$, which indicates the scatter. The results of the tensile tests for these fibers are shown in Table 1 and a SEM-image is shown in Figure 6.

The results indicate a high potential of the recycling process. The value for the fiber strength of the recycled fibers is on the level of new fibers, therefore, it indicates that the fibers are not damaged by oxidation.

The SEM images are showing clean fiber surfaces indicating a complete removal of the epoxy matrix and of the pyrolytic carbon residues.

\section{CONCLUSIONS}

In this study, the high potential of pyrolysis to recover carbon fibers from production scrap was successfully demonstrated. TGA together with investigations of the fiber surface was proved to be a good tool for the investigation of the pyrolysis process and the investigation of influences on the fiber properties. It was shown, that the partial oxidation of pyrolytic carbon from the carbon fiber surface is possible without seriously damaging the fibers.

Finally, optimized process parameters were determined from the experiments and an optimized pyrolysis test run in a semi-industrial pyrolysis plant was performed. The recycled fibers from this experiment exhibit excellent mechanical properties, which are 
on the level of new carbon fibers, and a fiber surface without pyrolytic carbon residues. The oven process developed and used by Refiber is a very good solution for the recovery of carbon fibers from composite waste. The recycled carbon fibers from THIS process have a high potential to replace new carbon fibers in CFRP products, therefore, it is possible to close the loop for CFRPs.

\section{ACKNOWLEDGMENT}

The authors would like to thank the Federal Ministry of Education and Research for funding this research project under contract 01RC-0064.

\section{REFERENCES}

1. Pickering, S.J. (2006). Recycling Technologies for Thermoset Composite Materials - Current Status, Composites Part A, 37(8): 1206-1215.

2. Schulte, K. and Ahlborn, H. (1997). Recycling Von kohlenstofffaserverstärkten Kunststoffen (CFK), DGM Informationsgesellschaft, Frankfurt, 21-26.

3. Meyer, L.O., Bartels, P., Fiedler, B., Ahlborn, H., and Schulte, K. (2005). A Practical Solution for Substancial Recycling of Carbon Fiber Reinforced Composites, In: Proceedings of the 3rd EcoComp, June 20 and 21, 2005, Stockholm, Sweden.

4. Montes-Moràn, M. and Young, R. (2002). Raman Spectroscopy Study of HM Carbon Fibers: Effect of Plasma Treatment on the Interfacial Properties of Single Fiber/Epoxy Composites, Part I: Fiber characterization, Carbon, 40(6): 845-855.

5. Liu, C.L., Dong, W.S., Song, J.R. and Liu, L. (2007). Evolution of Microstructure and Properties of Phenolic Fibers During Carbonization, Materials Science and Engineering A, 459: 347-354.

6. Lespade, P., Al-Jishi, R. and Dresselhaus, M.S. (1982). Model for Raman Scattering from Incompletely Graphitized Carbons, Carbon, 20(5): 427-431.

7. Bellenger, V.F., Fleishmann, E., Saporito, A. and Verdu, J. (1984). Thermogravimetric Study of Amine Cross-linked Epoxies, Polymer Degradation and Stability, 9(4): 195-208.

8. Rose, N., Le Bras, M., Delobel, R., Costes, B. and Henri, Y. (1993). Thermal Oxidative Degradation of an Epoxy Resin, Polymer Degradation and Stability, 42(3): 307-316.

9. Weibull, W. (1951). A Statistical Distribution Function of Wide Applicability, Journal of Applied Mechanics, 18: 293-297. 